\title{
Erratum to: Contrasting the early life histories of sympatric Arctic gadids Boreogadus saida and Arctogadus glacialis in the Canadian Beaufort Sea
}

\author{
Caroline Bouchard $^{1} \cdot$ Salomé Mollard $^{1,2} \cdot$ Keita Suzuki $^{3} \cdot$ Dominique Robert $^{4}$. \\ Louis Fortier ${ }^{1}$
}

Published online: 29 November 2016

(C) Springer-Verlag Berlin Heidelberg 2016

\section{Erratum to: Polar Biol (2016) 39:1005-1022 DOI 10.1007/s00300-014-1617-4}

The caption of Table 3 should read:

Summary of references on relationships between carbon content $(C$, in $\mu \mathrm{g})$, prosome (PL, in $\mathrm{mm})$ or total length ( $L$, in $\mathrm{mm}$ ) for the main prey of Boreogadus saida and Arctogadus glacialis early life stages. instead of:

Summary of references on relationships between carbon content $(C$, in $\mathrm{mg})$, prosome (PL, in $\mathrm{mm})$ or total length
( $L$, in $\mathrm{mm}$ ) for the main prey of Boreogadus saida and Arctogadus glacialis early life stages.

Also in Table 3, the equation for Ostracoda should read:

$C=0.346 \times \mathrm{e}^{3.868 \times L} \times 0.4$

instead of:

$C=0.346 \times \mathrm{e}^{3.868 \times L} \times 0,4$

This does not change the results presented in the text and in the figures.

The online version of the original article can be found under doi:10.1007/s00300-014-1617-4.

Caroline Bouchard

caroline.bouchard@qo.ulaval.ca

1 Québec-Océan, Département de Biologie, Université Laval, Quebec, QC G1V 0A6, Canada

2 Labex MER, Université de Bretagne Occidentale, 29238 Brest, France

3 Maizuru Fisheries Research Station, Field Science Education and Research Center, Kyoto University, Nagahama, Maizuru-shi, Kyoto 625-0086, Japan

4 Centre for Fisheries Ecosystems Research, Fisheries and Marine Institute, Memorial University, St. John's,

NL A1C 5R3, Canada 